\title{
Parental Knowledge of Foreign Body Aspiration: A Comparative Study between Saudis and Other Nations
}

\section{Abstract}

Introduction: Although foreign body aspiration (FBA) can be a life-threatening event, it still can be Preventable. One of the most important risk factors for FBA is a lack of knowledge by the caregivers. Moreover, there are only a few publications evaluating parental knowledge, and none of them address the parents' level of education.

Aim of the study: The primary aim is to evaluate parental knowledge of foreign body aspiration among Saudis, and to correlate FBA knowledge with parental level of education; the secondary aim is to choose the most suitable method to spread the knowledge of FBA prevention, and to compare parental knowledge of FBA between Saudis and other nations.

Method: A15 FBA-related items questionnaire was developed. The questionnaires were distributed to parents attending routine check up in different outpatient clinics across the two largest advanced secondary hospitals in Dammam city located in the Eastern Province of the Kingdom of Saudi Arabia.

Results: Out of the 500 questionnaires distributed, 452 were recovered and mothers answered most of them. Only17 questionnaires were incomplete and excluded, while 435 questionnaires were analyzed. The studied group was divided into two groups based on level of education; the first group is the middle and high school graduates and was about $55 \%$, and the rest, $45 \%$, were the college graduates. One third of the parents in both studied groups did not recognize a small toy, and/or peanuts as a cause of FBA. Regarding clinical presentation of FBA, $14 \%$ and $27 \%$ of mothers did not know that sudden choking and coughing were symptoms suggesting FBA, respectively. No statistical significant difference in both studied groups ( $\mathrm{p}$-value $=0.785$ ).

Conclusion: A substantial number of parents globally including Saudis lack knowledge regarding FBA even among college graduates. To prevent FBA, and to make timely diagnoses, parents should have a thorough continuous education regarding FBA risks, presentation, and management.

Keywords

Foreign Body Aspiration; Parental; Knowledge; Education
Research Article

Volume 2 Issue 1 - 2015

Zeinab AlQudehy ${ }^{1 *}$, Hussein Al-Sheif ${ }^{2}$ and Ghada Al-Qudaihi ${ }^{3}$

${ }^{1}$ Department of Otorhinolaryngology, Dammam Medical Complex, Saudi Arabia

${ }^{2}$ Department of Otorhinolaryngology Dammam Medical Complex, Saudi Arabia

${ }^{3}$ Epidemiology Department, Qatif Central Hospital, Saudi Arabia

*Corresponding author: Zeinab AlQudehy, Department of Otorhinolaryngology, Dammam Medical Complex,P.O.Box 508, Dhahran 31311, Saudi Arabia, Tel: 00966504804838; Fax: 0096638901950; Email: drzeinabent@gmail.com

Received: December 26, 2014Published: January 09, 2015

\section{Abbreviations}

FBA: Foreign Body Aspiration; SG: School Graduates; CG: College Graduates; IL: Illiterates

\section{Introduction}

Children have an increased risk of foreign body aspiration (FBA) compared to adults, with approximately $80 \%$ of foreign body inhalation occurring in children below three years of age [1-5]. Aspiration of foreign body has a significant morbidity rate and can cause mortality in about $7 \%$ of cases [6-21]. Although there have been significant advances in pediatric endoscopic airway management, the occurrence of FBA has not changed significantly [3].The increased risk of aspiration in children during the first three years of life is attributed to many factors including: inadequately developed posterior dentition, immature neuromuscular mechanisms of both deglutition and airway protection, and the ubiquitous tendency of children below
3 years of age to put objects into their mouths [22]. Another contributory factor of FBA is failure to provide adequate supervision of susceptible children with easy access to small objects [23]. Clinical presentation of foreign body aspiration is often widely variable, from unobserved or minimal symptoms to sever respiratory compromise and even death [24].

FBA symptoms and signs produced depend upon the size, location, nature and time since lodgment of tracheo-bronchial foreign body [25]. Prevention of FBA is better than treatment and it is the most critical step in avoiding FBA related mortality and morbidity [26]. Public awareness regarding the risk of FBA in children should be increased. However, there have been only a few reports addressing the parental knowledge regarding FBA, the effect of educational level of the caregivers in reducing the incidence of trachea bronchial foreign body in children, and the public's awareness, which is the most vital [27].

\section{The Aim of Our Study}


The primary aim is to evaluate parental knowledge of foreign body aspiration among Saudis, correlate FBA knowledge with parental level of education; the secondary aim to choose the most suitable method to spread the knowledge of FBA prevention, and to compare parental knowledge of FBA between Saudis and other nations.

\section{Method \& Material}

\section{Study Design}

This is a cross sectional, self-administered knowledge survey. The calculated sample size needed was 380 subjects, based on $80 \%$ power of the study and $20 \%$ drop out. A computergenerated list for random sampling method was used. The study was carried out over a period of 3 months; August-October 2013 in 2 main hospitals in Dammam City, Eastern Province of Saudi Arabia; namely Dammam Complex and Maternity and Children Hospitals. Local Hospital Scientific committee approval was obtained before proceeding with the study.

The questionnaire survey was distributed to all parents, regardless of parity, attending routine checkup in different outpatient clinics during working days' mornings and afternoons across the two largest advanced secondary hospitals in Dammam city. Parents were approached through the collecting data team, which explained the study objectives and questionnaire setup to them. The parents were asked to fill out the questionnaire before entering the check-up appointment without consulting other Persons. Parents accompanying sick child were excluded from the study.

The questionnaire is comprised of 2 parts. The first part addresses the parental demographic background including age, gender, educational level, number of kids, and any history of FBA within the family. The second part contains 15 close-ended questions eliciting parents' general knowledge on foreign body aspiration, clinical presentation, management and prevention.

The questionnaire was originally developed in English, and translated into the Arabic Language, since it's the citizen's spoken language. Only the English version is, however, presented in the appendix (Appendix 1). The Arabic version was administered to all parents by the data collector team.

\section{Statistical Method For Analysis}

Data entry and analysis were done by SPSS software (Version 21). The frequencies of all the studied variables were calculated. In comparison, Chi-square $\left(X^{2}\right)$ and p-value were used for categorical variables. A p-value $<0.05$ was considered to be statistically significant. Multivariate analysis was used to estimate the effects of the participants' background characteristics on parental FBA general knowledge. The t-test of independent sample was used to determine if there is a statistical significant difference between the school graduate parents and the college graduate parents regarding their knowledge of FBA.

\section{Results \& Discussion}

\section{Results}

Out of the 500 questionnaires distributed, 452 were recovered with a response rate of $90.4 \%$. Only 17 questionnaires were incomplete and excluded; and 435 questionnaires were analyzed (87\%). Mothers completed $71 \%$ of the questionnaires, and fathers in $29 \%$. The studied group was divided mainly into two groups based on level of education: the educated group, with the majority of $98.2 \%$, and the illiterate group $(1.8 \%)$. The educated group was subdivided into two: the middle and high school graduates (SG), which were about 55.9\%; and the college graduates (CG), which were about $44.1 \%$.

The age of parents involved in our study ranges between 20 to 63 years; with an average of 33.5 years in the educated group (both SG \& CG), and 47.3 years in non-educated or illiterate group (IL). The focus of the studied group was on those who have one or more children. $74 \%$ of parents who filled the FBA questionnaire were those who had only one child, as the demographic data is illustrated in (Table 1).

For simplicity, we divided the results of the studied population into three groups, based on educational level, that is school graduate (SG), college graduate (CG), and finally illiterate (IL).During the interpretation of our results, we have chosen to refer to knowledge scale as good or poor knowledge of FBA. We put a measure of $70 \%$ as a cut off for good knowledge. (Table 2) shows the general knowledge, and clinical presentation, management and prevention aspects through 14 questions in our designed questionnaires. In each group separately, the table addresses the percentages of true and false answers, and the uncertain answers, as well as the overall knowledge of FBA in the three groups of parents. Surprisingly, $80 \%$ of college graduate parents did not identify peanuts as a cause of foreign body aspiration while all the parents from the illiterate group know that peanut is a cause of FBA, and that FBA is common in children

Table 1: Demographic data of the study group with regards to gender, level of education, and number / percentage of parents with one child.

\begin{tabular}{|c|c|c|}
\hline Study population & \multicolumn{2}{|l|}{437 parents } \\
\hline Age & \multicolumn{2}{|c|}{$\begin{array}{l}\text { Range: } 20-63 \text { years } \\
\text { Average: } 33.5 \text { yrs. in SG \& CG groups }\end{array}$} \\
\hline \multicolumn{2}{|r|}{ 47.3 yrs. in IL group } & $\begin{array}{l}\text { Number } \\
\text { (Percentage) }\end{array}$ \\
\hline Gender distribution & $\begin{array}{l}\text { Male }(M)=124(21 \%) \\
\text { Female }(F)=313(69 \%)\end{array}$ & $\begin{array}{l}124(21 \%) \\
313(69 \%)\end{array}$ \\
\hline Parents with one child & & $323(74 \%)$ \\
\hline Level of education & $\begin{array}{l}\text { Illiterate (IL) } \\
\text { School Graduates (SG) } \\
\text { College Graduates (CG) }\end{array}$ & $\begin{array}{l}8(1.8 \%) \\
F=4 \\
M=4 \\
239(55.9 \%) \\
F=133 \\
M=56 \\
198(44.1 \%) \\
F=126 \\
M=65\end{array}$ \\
\hline
\end{tabular}


Table 2: Parental General Knowledge of foreign body aspirate stratified by parental level of education, among Saudi in two major hospitals in Eastern Province.

\begin{tabular}{|c|c|c|c|c|c|c|c|}
\hline \multirow{2}{*}{ Question Type } & \multirow{2}{*}{ Question (s) } & \multicolumn{3}{|c|}{ Parents Educational Level } & \multirow{2}{*}{$\begin{array}{c}\text { Over all } \\
\text { knowledge }\end{array}$} & \multirow{2}{*}{$\begin{array}{c}\text { Poor } \\
\text { knowledge }\end{array}$} & \multirow{2}{*}{ Good knowledge } \\
\hline & & IL* ( ) \% & SGT ( ) \% & CG† ( ) \% & & & \\
\hline \multirow{8}{*}{$\begin{array}{l}\text { General Knowledge } \\
\text { Qs (8) }\end{array}$} & Nuts could cause FBA & $(100) \%$ & $(62) \%$ & $(66) \%$ & $76 \%$ & & $\mathrm{X}$ \\
\hline & $\begin{array}{l}\text { FBA most frequently seen in } \\
0-2 \text { yrs. }\end{array}$ & $(100) \%$ & $(56) \%$ & $(55) \%$ & $70 \%$ & & $\mathrm{X}$ \\
\hline & $\begin{array}{l}\text { Peanuts should not be given to } \\
\text { children }<3 \text { yrs. }\end{array}$ & $(75) \%$ & $(70) \%$ & $(55) \%$ & $67 \%$ & $\mathrm{X}$ & \\
\hline & $\begin{array}{l}\text { Small toys can cause FBA in } \\
\text { children }<3 \text { yrs. }\end{array}$ & $(75) \%$ & $(87) \%$ & $(78) \%$ & $80 \%$ & & $\mathrm{X}$ \\
\hline & $\begin{array}{l}\text { No supervision is needed when } \\
\text { toddlers are playing }\end{array}$ & $(25) \%$ & $(65) \%$ & $(76) \%$ & $55 \%$ & $\mathrm{X}$ & \\
\hline & $\begin{array}{l}\text { Child Crying while holding small } \\
\text { toys is not recommended. }\end{array}$ & $(50) \%$ & $(72) \%$ & $(76) \%$ & $66 \%$ & $\mathrm{X}$ & \\
\hline & Hard nuts beneficial to toddlers & $(50) \%$ & $(72) \%$ & $(80) \%$ & $67 \%$ & $\mathrm{X}$ & \\
\hline & $\begin{array}{l}\text { It's not recommended that } \\
\text { children Walk or laugh while }\end{array}$ & $(50) \%$ & $(88) \%$ & $(90) \%$ & $76 \%$ & & $\mathrm{X}$ \\
\hline Total & Eating. & $53 \%$ & $71 \%$ & $72 \%$ & $65 \%$ & $\mathrm{X}$ & \\
\hline \multirow{3}{*}{$\begin{array}{l}\text { Clinical Presentation } \\
\text { Qs (3) }\end{array}$} & $\begin{array}{l}\text { Sudden Chocking symptom of } \\
\text { FBA }\end{array}$ & $(75) \%$ & $(69) \%$ & $(78) \%$ & $74 \%$ & & \\
\hline & $\begin{array}{l}\text { Sudden Coughing } \\
\text { symptom of FBA }\end{array}$ & $(75) \%$ & $(62) \%$ & $(67) \%$ & $68 \%$ & $\mathrm{X}$ & \\
\hline & Absence of symptoms is & $(0) \%$ & $(27) \%$ & $(32) \%$ & $20 \%$ & $\mathrm{X}$ & \\
\hline Total & reassuring signs & $50 \%$ & $53 \%$ & $59 \%$ & $54 \%$ & $\mathrm{X}$ & \\
\hline \multirow{2}{*}{ Management Qs (2) } & $\begin{array}{l}\text { FBA requires Immediate } \\
\text { medical advise }\end{array}$ & $(100) \%$ & $(96) \%$ & (99)\% & $98 \%$ & & $\mathrm{X}$ \\
\hline & $\begin{array}{l}\text { Inform treating doctor about } \\
\text { change in health after FBA }\end{array}$ & $(100) \%$ & $(98) \%$ & $(99) \%$ & $99 \%$ & & $\mathrm{X}$ \\
\hline Prevention Q (1) & $\begin{array}{l}\text { change in health after FBA More } \\
\text { education is needed for FBA }\end{array}$ & $(100) \%$ & $(95) \%$ & $(98) \%$ & $98 \%$ & & $\mathrm{X}$ \\
\hline Total & & $100 \%$ & $96 \%$ & $99 \%$ & $98 \%$ & & $\mathrm{X}$ \\
\hline
\end{tabular}

*IL: Illiterate \SG: School Graduate, †CG: College Graduate

under two years of age. Almost half of the college graduate parents were not convince by the fact that peanut should not be given to children below three years of age. In the illiterate parents' group, 50\% thought that supervision on children under three years of age while playing in not needed. (Chart 1) shows chart representation of the percentages of the parental general unawareness of FBA, as demonstrated across all 8 FBA-related items in our questionnaires. In regards of the clinical presentation of FBA, $14 \%$ and $27 \%$ of mothers, in SG \& CG respectively, did not know that sudden choking and coughing were symptoms suggesting FBA. The overall knowledge of clinical presentation of FBA was low in all three groups (SG, CG, and IL) with 53\%, 59\%, and $50 \%$ respectively, as shown in (Chart 2). Parental knowledge regarding management of FBA cases was excellent in all three studied groups, with no differences among the three groups, as evident in (Chart 3). The overall parental knowledge regarding FBA risk factors, presentations, management and prevention was not correlated with neither the age of the parents nor the parity. 


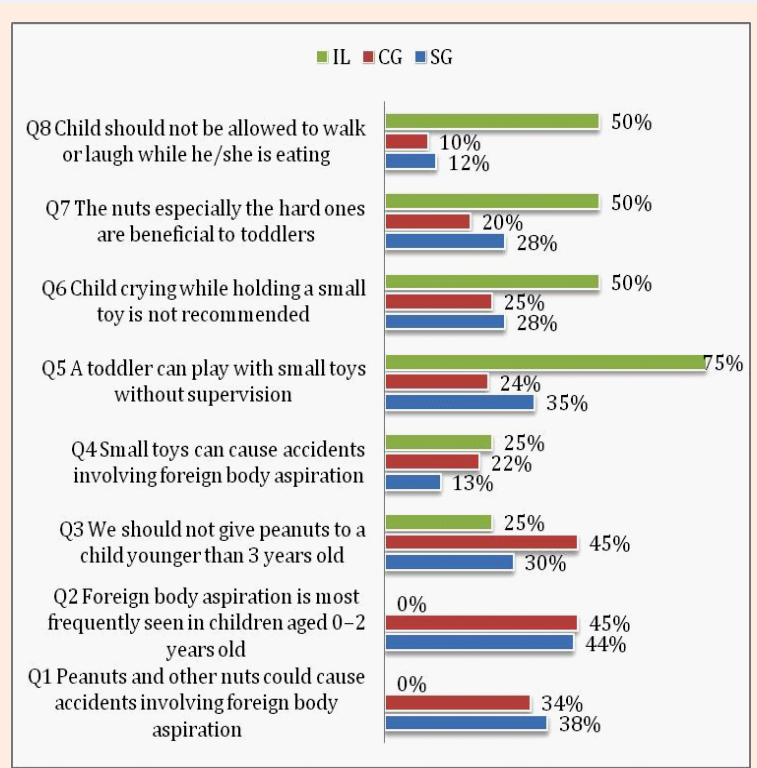

Chart 1: Demonstrated chart presentation of lack of parental FBA general knowledge among the three studied groups (school graduates, college graduates, and illiterates).

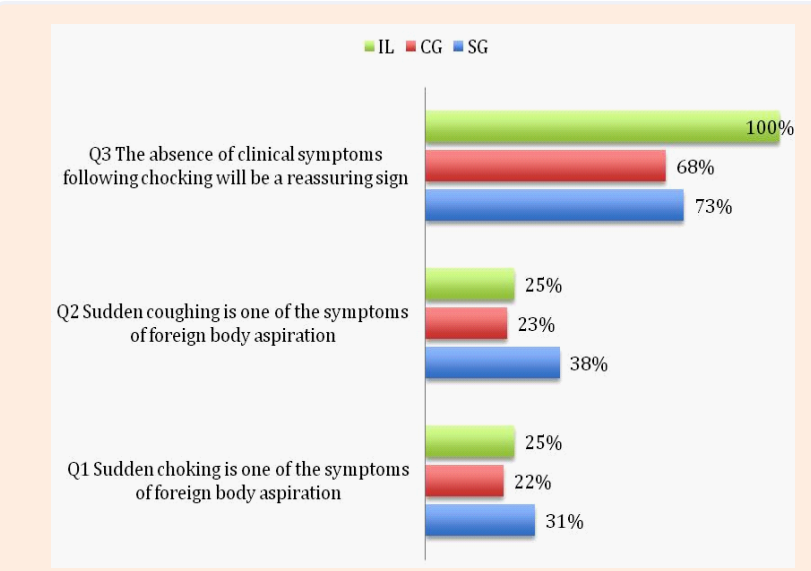

Chart 2: Showed t-test of independent sample, which was used to determine if there is a statistical significance difference between the school graduate parents with the college graduate parents regarding their knowledge of FBA.

The t-test of independent sample was used to determine if there is a statistical significant difference between the school graduate parents and the college graduate parents regarding their knowledge of FBA. The collected data regarding FBA parents' knowledge from both school and college graduates groups failed to reject the hypothesis that there is a statistical significant difference between the two groups in their true answers (Table $3)$.

The three groups of parents, that is SG, CG, and IL, agreed that more education regarding risk of foreign body inhalation is needed. Pamphlets, educational campaign, use of media like T.V., and education during maternity appointments were the suggested method to improve public education regarding FBA.
The preferable education method was a combination of the four suggested methods written in the questionnaire, and was selected by more than half the studied groups. Pamphlets were selected by $3 \%$ of the surveyed parents regardless of their level of education.

\section{Discussion}

Foreign body aspiration (FBA) has been recognized as one of the most frequent injuries occurring among toddlers and young children. It is a common cause for a respiratory emergency in young children especially below the age of four years, and can be a life-threatening event [26]. Almost 2.5 million children are affected each year in the United States, with an annual mortality rate of trachea bronchial FBA of approximately 1\% [27]. Across the world, eight persons die as result of FBA, mostly children [28]. Moreover, FBA is a cause of death in $44 \%$ of infants younger than one year, and in $7 \%$ of pre-school children, according to the data of National Center for Health Statistics 1993-1995 [29]. In a nationwide survey that was conducted in Japan, $78.6 \%$ of 163 cases of FBA found that the children were younger than 3 years old, while $85.3 \%$ of whom had foreign bodies that were organic in nature such as nuts and beans [30].

The clinical presentation of FBA is variable, and often the diagnoses are made late. Absence of choking episode does not rule out FBA and may be a risk factor or diagnostic delay [28-30]. A combination of signs and symptoms are usual presentation of patients with FBA, with cough and wheezing being the most common symptoms followed by breathlessness and the commonest sign was diminished breath sounds on the affected side [24]. FBA classical diagnostic triad includes cough, wheeze and decreased breath sounds seen in most of the cases and has also been reported by many authors [24, 31-33]. Frequently FBA symptoms may mimic intermittent trachea bronchitis, recurrent pneumonia or asthma and children may be treated with antibiotics and steroids, which may further mask the symptoms and lead to delay in diagnosis [31]. Specifically, for this reason, FBA should be considered in all children with atypical or prolonged pulmonary symptoms. The delay in diagnoses can lead to a spectrum of complications ranging from life-

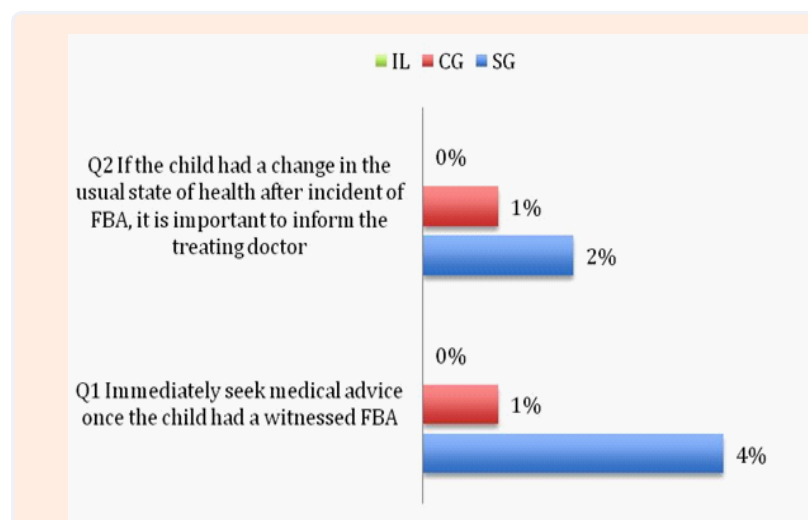

Chart 3: Chart represents excellent parental knowledge of FBA management and need for further education for better prevention among all groups of studied parents 
Table 3: Showed t-test of independent sample, which was used to determine if there is a statistical significance difference between the school graduate parents with the college graduate parents regarding their knowledge of FBA.

\section{Independent Samples Test}

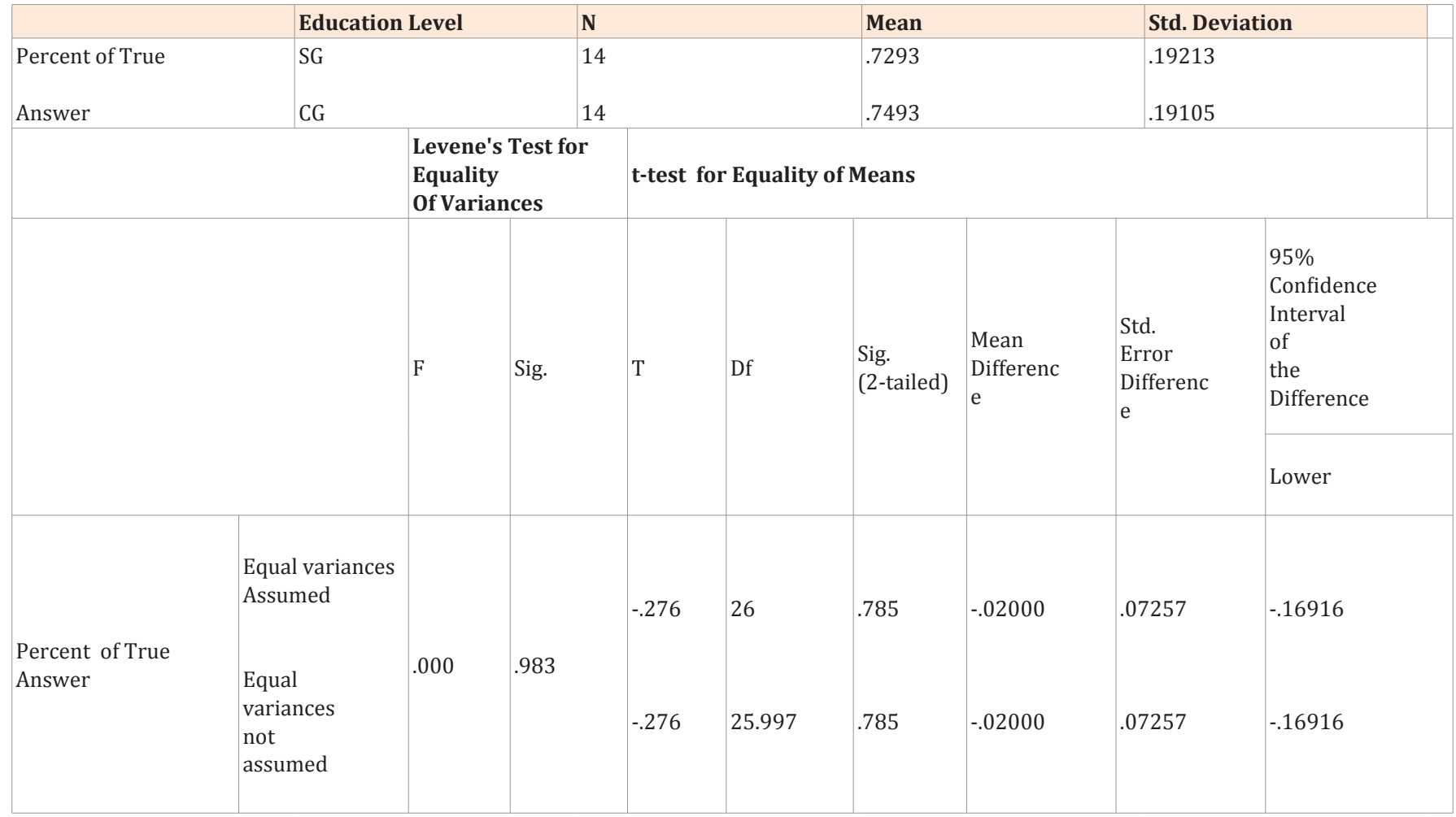

N: Number of the questionnaires, Mean: Mean of the true answers for the school graduates(SG)\& College Graduates(CG)

threatening airway obstruction, to chronic wheezing, recurrent pneumonia, or failure to thrive $[17,27,34,35]$. The nationwide survey conducted in Japan revealed that diagnoses of inhaled FB were delayed by more than 24 hours in approximately half of the patients. Although suspected symptoms, such as episodes of chocking and sudden coughing, were present in about $65 \%$ of these cases [36].

Delay in FBA diagnosis for more than a week can occur in $29 \%$ of the cases. While in $10 \%$ of the cases, the delay was found to be more than 30 days. If misdiagnosed, it may cause chronic and irreversible lung injury [33]. Several factors are associated with delayed diagnosis; two of these are physician- and parentrelated factors [6]. One of the parent related factors is that parents are unaware of clinical signs suggestive of FBA, such as sudden choking and coughing [37], as shown in this study. Parents will not suspect FBA in their symptomatic child if they did not know what are typical symptoms and signs of FBA. In our current study, $40 \%$ of parents consider absence of symptoms in case of FBA as reassuring sign. According to a study carried out by Higuchi et al. 2009, it was detected that $27.7 \%$ of parents participating in the study were unfamiliar to the symptoms of FBA. Similarly, we found in our study that almost $25 \%$ of parents did not identify the symptoms of FBA [36].

One of the most important risk factors of FBA is a lack of knowledge of parents or care giver. In a European Union-based surveillance of FBA, the Suzy Safe registry showed that in $40 \%$ of FBA cases involving a child younger than 1 year of age, an adult was present [33]. Many cases of FBA can be preventable. In order to prevent foreign body inhalation, and to assure early diagnoses for appropriate management, public awareness should be enhanced, specifically at a parental level [30]. However, only few reports are available evaluating parental knowledge regarding FBA in a general population. In this study, $18 \%$ of parents were unsure whether peanuts are considered as an identifiable cause of FBA; and almost the same percentage disagreed that peanuts and hard nuts should not be given for children under three years of age. Even though most studies have shown that peanuts are the most frequent cause of FBA worldwide [6,35-40].

Our study is considered as the only conducted study among Saudi parents addressing their knowledge regarding foreign body aspiration. A similar study encountered in extensive literature review is the one conducted by Higuchi et al. [27] to assess mothers knowledge of FBA, and was through a cross sectional survey from May 2010 through August 2010 using 8-questioned, self-administered questionnaire. Total of 1766 questionnaire distributed in 12 regional community centers in Toyama, Japan and 1490 completely filled questionnaires collected. The aim of his study was to evaluate parents' knowledge regarding foreign body aspiration, and determine the factors that are associated with lack of knowledge such as age of the parent and the number of children. Similar to our study, the parents were asked to fill out 
the questionnaire by the end of the check-up without consulting other persons; and the questions focused on knowledge of the risk factors and clinical presentation of FBA and on how to prevent FBA [25]. The conclusion of Higuchi et al. [27] study was that the substantial number of mothers lack knowledge regarding FBA, which was more pronounced in mothers with children younger than 12 months, and mothers with one child. Moreover, our study addresses both mothers and fathers (29\% by fathers). In both, we could not establish a correlation between age of the parent or the number of children. (Chart 4) demonstrates a comparison between lack of foreign body aspiration knowledge in regards to general knowledge and clinical presentation among Saudis and Japanese.

One limitations of our study is that although this study was conducted in two centers, which are considered the largest governmental hospitals in the most crowded city on the east coast of the Kingdom of Saudi Arabia (KSA), it has still the disadvantage of geographical limitations owing to the large area of KSA. The variability in socioeconomic status of different family might be considered as a factor affecting the knowledge of FBA, which was not included in our current study. In addition to that, the fact that the questionnaire used in this study and Higuchi et al. were not validated for evaluating parent's knowledge regarding FBA

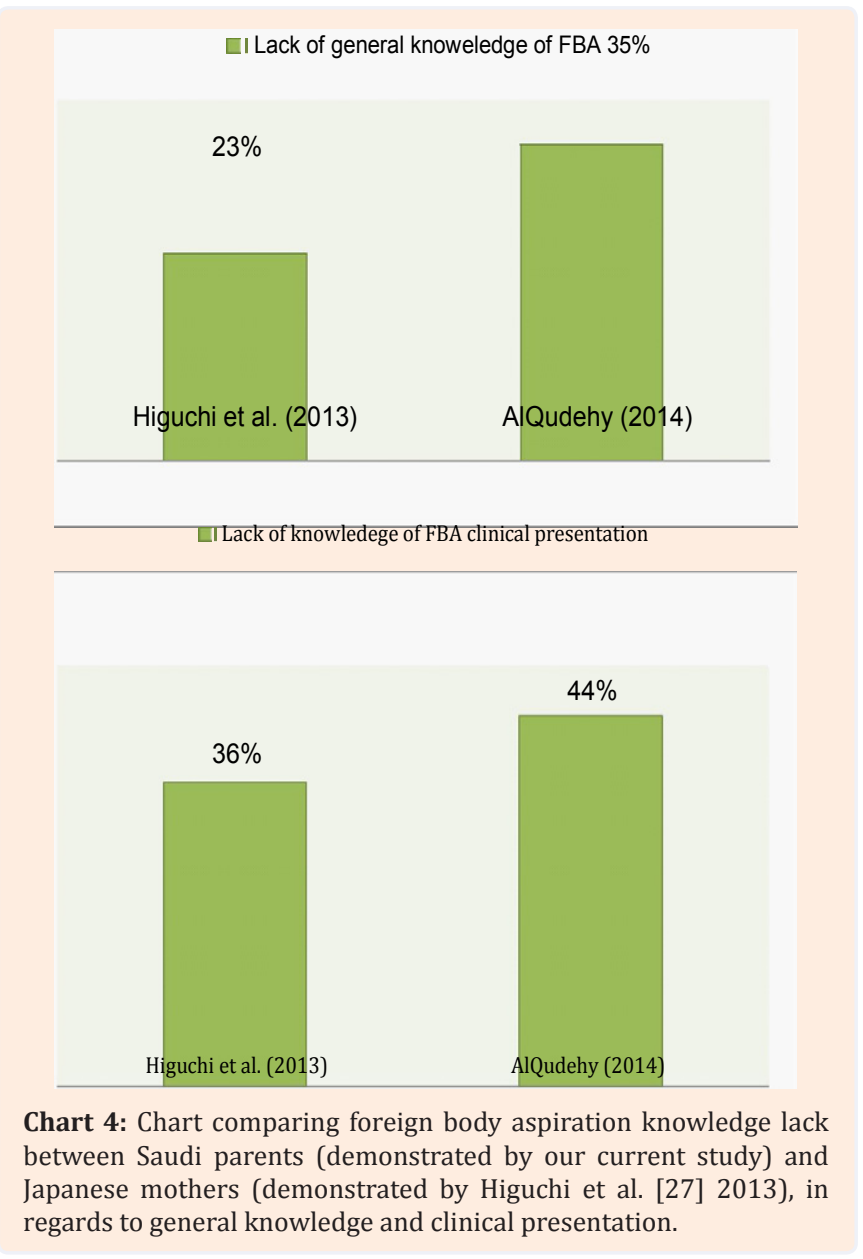

is also considered as a disadvantage. Although both developed the questionnaire by referring to the results of the nationwide survey of FBA cases [36], further studies are needed to establish the type of information that is necessary for parents to prevent FBA in their children.

The study showed a present, constant agreement regarding the need for more education directed to the public regarding FBA. In 2007, Karatzanis evaluated the effects of a media campaign for public awareness of FBA as judged by the total number of bronchoscopies for FBA which was significantly decreased, compared to the time period before the introduction of the campaign. The suggested education methods varied from pamphlets, educational campaign, use of media such as T.V., and education during maternity appointments. The current study showed that the preferable education method is a combination of the four suggested methods, and was selected in more than half of the time. Pamphlets were selected by $3 \%$ of the surveyed parents regardless in their level of education. Based in the parents' choices, utilization of all mentioned educational methods would assemble the optimal plan for our nation.

\section{Conclusion}

FB aspiration is a commonly encountered life-threatening event in pediatric patients that can manifest various symptoms. Although there have been significant advances in airway management and endoscopic technology, the incidence of FBA has not changed significantly. One of the most important risk factors for FBA is a lack of knowledge of parents or caregiver, with substantial number of global parents including Saudis lack knowledge regarding FBA, even among college graduates. To prevent FBA, and to make timely diagnoses, parents should have a thorough, continuous education regarding FBA, risks, presentation, and management.

\section{References}

1. Cataneo AJ, Reibscheid SM, Ruiz Junior RL, Ferrari GF (1997) Foreign body in the tracheobronchial tree. Clin Pediatr 36(12): 701-706.

2. Oguz F, Citak A, Unuvar E, Sidal M (2000) Airway foreign bodies in childhood. Int J Pediatr Otorhinolaryngol 52(1): 11-16.

3. Pinzoni F, Boniotti C, Molinaro SM, Baraldi A, Berlucchi M (2007) Inhaled foreign bodies in pediatric patients: review of personal experience. Int J Pediatr Otorhinolaryngol 71(12): 1897-1903.

4. Ciftci AO, Bingol-Kologlu M, Senocak ME, Tanyel FC, Buyukpamukcu N (2003) Bronchoscopy for evaluation of foreign body aspiration in children. J Pediatr Surg 38(8): 1170-1176.

5. Mani N, Soma M, Massey S, Albert D, Bailey CM (2009) Removal of inhaled foreign bodies - middle of the night or the next morning? Int J Pediatr Otorhinolaryngol 73(8): 1085-1089.

6. Tan HK, Brown K, McGill T, Kenna MA, Lund DP, et al. (2000) Airway foreign bodies (FB): a 10-year review. Int J Pediatr Otorhinolaryngol 56(2): 91-99.

7. Zaytoun GM, Rouadi PW, Baki DH (2000) Endoscopic management of foreign bodies in the tracheobronchial tree: predictive factors for complications. Otolaryngol Head Neck Surg 123(3): 311-316. 
8. $\mathrm{Mu} \mathrm{L}, \mathrm{He} \mathrm{P}$, Sun D (1991) Inhalation of foreign bodies in Chinese children: a review of 400 cases. Laryngoscope 101(6 Pt 1): 657-660.

9. Metrangolo S, Monetti C, Meneghini L, Zadra N, Giusti F (1999) Eight years' experience with foreign-body aspiration in children: what is really important for a timely diagnosis? J Pediatr Surg 34(8): 12291231.

10. Black RE, Johnson DG, Matlak ME (1994) Bronchoscopic removal of aspirated foreign bodies in children. J Pediatr Surg 29(5): 682-684.

11.Brkic F, Delibegovic-Dedic S, Hajdarovic D (2001) Bronchoscopic removal of foreign bodies from children in Bosnia and Herzegovina: experience with 230 patients. Int J Pediatr Otorhinolaryngol. 60(3): 193-196.

12. Emir H, Tekant G, Besik C, Elicevik M, Senyuz OF, et al. (2001) Bronchoscopicremoval of tracheobronchial foreign bodies: value of patient history and timing. Pediatr Surg Int 17 (2-3): 85-87.

13. Skoulakis CE, Doxas PG, Papadakis CE, Proimos E, Christodoulou P et al. (2000) Bronchoscopy for foreign body removal in children. A review and analysis of 210 cases. Int J Pediatr Otorhinolaryngol 53(2): 143-148.

14. Bittencourt PF, Camargos PA, Scheinmann P, de Blic J (2006) Foreign body aspiration: clinical, radiological findings and factors associated with its late removal. Int J Pediatr Otorhinolaryngol 70(5): 879-884

15. Heyer CM, Bollmeier ME, Rossler L, Nuesslein TG, Stephan V, et al. (2006) Evaluation of clinical, radiologic, and laboratory prebronchoscopy findings in children with suspected foreign body aspiration. J Pediatr Surg 41(11): 1882-1888.

16. Cataneo AJ, Cataneo DC, Ruiz Jr RL (2008) Management of tracheobronchial foreign body in children. Pediatr Surg Int 24(2): 151-156.

17. Sersar SI, Rizk WH, Bilal M, El Diasty MM, Eltantawy TA, et al. (2006) Inhaled foreign bodies: presentation, management and value of history and plain chest radiography in delayed presentation. Otolaryngol Head Neck Surg 134(1): 92-99.

18. Hua Huia, Li Naa, Chen J Zhijuna, Zhu G Fugaoa, Sun Yan (2008) Therapeutic experience from 1428 patients with pediatric tracheobronchial foreign body. Pediatr Surg 43(4): 718-721.

19. Aydogan LB, Tuncer U, Soylu L, Kiroglu M, Ozsahinoglu C (2006) Rigid bronchoscopy for the suspicion of foreign body in the airway. Int J Pediatr Otorhinolaryngol 70(5): 823-828.

20. Ciftci AO, Bingol-Kologlu M, Senocak ME, Tanyel FC, Buyukpamukcu NB (2003) Bronchoscopy for evaluation of foreign body aspiration in children. J Pediatr Surg 38(8): 1170-1176.

21. Ayed AK, Jafar AM, Owayed A (2003) Foreign body aspiration in children: diagnosis and treatment. Pediatr Surg Int 19(6): 485-488.

22. Daniilidis J, Symeonidis B, Triaridis K, Kouloulas A (1997) Foreign body in the airways: a review of 90 cases. Arch Otolaryngol 103(10): 570-573.

23. Pan H, Lu Y, Shi L, Pan X, Li L, et al. (2012) Similarities and differences in aspirated tracheobronchial foreign bodies inpatients under the age of 3 years. Int J Pediatr Otorhinolaryngol 76(6): 911-914.

24. Naragund AI, Mudhol RS, Harugop AS, Patil PH, Hajare PS, et al. (2014) Tracheo-Bronchial Foreign Body Aspiration in Children: A One Year Descriptive Study. Indian J Otolaryngol Head Neck Surg 66(Suppl 1): 180-185.

25. Darrow DH, Holinger (2002) Foreign bodies of the larynx, trachea and bronchi. In: Bluestone CD, et al. (Eds.), Paediatric otolaryngology. ( $4^{\text {th }}$ edn), WB Saunders Company, Philadelphia, pp. 1543-1557.

26. Passali D, Lauriello M, Bellussi L, Passali GC, Passali FM, et al. (2010) Foreign body inhalation in children: an update. Acta Otorhinolaryngol Ital 30(1): 27-32.

27. Higuchi O, Adachi Y, Adachi YS, Taneichi H, Ichimaru T, et al. (2013) Mothers' knowledge about foreign body aspiration in young children. Int J Pediatr Otorhinolaryngol 77(1): 41-44.

28. Sadan N, Raz A, Wolach B (1995) Impact of community educational programs on foreign body aspiration in Israel. Eur J Pediatr I54(10): 859-862.

29. Karatzanis AD, Vardouniotis A, Moschandreas J, Prokopakis EP, Michailidou E, et al. (2007) The risk of foreign body aspiration in children can be reduced with proper education of the general population. Int J Pediatr Otorhinolaryngol 71(2): 311-315.

30. Tomaske M, Gerber AC, Stocker S, Weiss M (2006) Tracheobronchial foreign body aspiration in children-diagnostic value of symptomsand signs. Swiss Med Wkly 136(33-34): 533-538.

31. Yalcin S (2011) The Child and the Domestic Accidents.

32. Higuchi O, Adachi Y, Ichimaru T, Asai M, Kawasaki K (2009) Foreign body aspiration in children: a nationwide survey in Japan. Int J Pediatr Otorhinolaryngol 73(5): 659-661.

33. Kaur K, Sonkhya N, Bapna AS (2002) Foreign bodies in the tracheobronchial tree: a prospective study of 50 cases. Indian JOtolaryngol Head Neck Surg 54(2): 30-34.

34. McGuirt WF, Holmes KD, Feehs R, Browne JD (1988) Tracheobronchial foreign Bodies. Laryngoscope 98(6 Pt 1): 615-618.

35. Merchant SN, Kirtane MV, Shah KL, Karnik PP (1984) Foreign bodies in the bronchi (a 10 year review of 132 cases). J Postgrad Med 30(4): 219-223.

36. Gerbaka B, Azar J, Rassi B Foreign body inhalation in children: a retrospective study about 100 cases. J Med Liban 45(1): 10-18.

37. Kugelman A, Shaoul R, Goldsher M, Srugo I (2006) Persistent cough and failure to thrive: a presentation of foreign body aspiration in a child with asthma. Pediatrics 117(5): e1057-e1060.

38. Karakoc F, Cakir E, Ersu R, Uyan ZS, Colak B, et al. (2007) Late diagnosis of foreign body aspiration in children with chronic respiratory symptoms. Int J Pediatr Otorhinolaryngol 71(2): 241-246.

39. Tang FL, Chen MZ, Du ZL, Zou CC, Zhao YZ (2006) Fibrobronchoscopic treatment of foreign body aspiration in children: an experience of 5 years in Hangzhou City, China. J Pediatr Surg 41 (1): e1-e5.

40. Foltran F, Ballali S, Passali FM, Kern E, Morra B, et al. (2012) Foreign bodies in the airways: a meta-analysis of published papers. Int J Pediatr Otorhinolaryngol 76(Suppl 1): S12-S19. 